\title{
Shovels and swords: How realistic and fantastical themes affect children's word learning
}

\author{
Deena Skolnick Weisberg a,*, Hande Ilgaz ${ }^{\mathrm{b}}$, \\ Kathy Hirsh-Pasek ${ }^{\mathrm{c}}$, Roberta Golinkoff ${ }^{\mathrm{d}}$, \\ Ageliki Nicolopoulou $^{\mathrm{e}}$, David K. Dickinson ${ }^{\mathrm{f}}$
}

a University of Pennsylvania, United States

b Bilkent University, Turkey

c Temple University, United States

d University of Delaware, United States

e Lehigh University, United States

f Vanderbilt University, United States

\section{A R T I C L E I N F O}

\section{Keywords:}

Word learning

Fantasy

Bookreading

Guided play

Low-income preschools

\begin{abstract}
A B S T R A C T
Research has shown that storybooks and play sessions help preschool children learn vocabulary, thereby benefiting their language and school readiness skills. But the kind of content that leads to optimal vocabulary learning - realistic or fantastical - remains largely unexplored. We investigate this issue as part of a large-scale study of vocabulary learning in low-income classrooms. Preschoolers $(N=154)$ learned 20 new words over the course of a two-week intervention. These words were taught using either realistic (e.g., farms) or fantastical (e.g., dragons) storybooks and toys. Children learned the new words in both conditions, and their comprehension knowledge did not differ across conditions. However, children who engaged in stories and play with a fantastical theme showed significantly greater gains in their production knowledge. Reasons for and implications of this result are discussed.
\end{abstract}

(c) 2014 Elsevier Inc. All rights reserved.

\footnotetext{
* Corresponding author at: Department of Psychology, University of Pennsylvania, 3720 Walnut Street, Solomon Labs, Philadelphia, PA 19104, United States. Tel.: +1 2158985228.

E-mail address: deena.weisberg@psych.upenn.edu (D.S. Weisberg).
} 
What is the best way to encourage learning in preschool-aged children? Does children's learning vary depending on content - whether it contains realistic themes of cooks and firefighters or fantastical themes of monsters and fairies? We investigate this question by examining how realistic and fantastical themes affect children's learning of new vocabulary words. To anticipate, our results suggest that stories with fantastical themes, which include entities or events that cannot occur in reality, can boost children's vocabulary learning more effectively than stories with realistic themes.

We have chosen to focus on word learning because children's early language abilities can have profound effects on their later achievement. Children's linguistic competence in preschool is highly related to later language ability (Dickinson, Golinkoff \& Hirsh-Pasek, 2010; NICHD, 2005; Sénéchal, 2006; Storch \& Whitehurst, 2002), which in turn predicts school readiness skills, reading comprehension, and overall academic achievement (Dickinson \& McCabe, 2001; Gershoff, 2003). Given these connections, it is clear that fostering children's language skills and vocabulary in preschool is important to later academic success.

Such attention to language is even more important for children from lower-income backgrounds. These children enter kindergarten knowing many fewer words than higher-income children (Lee \& Burkham, 2002), an achievement gap that does not close over the course of the school years and that may indeed widen (Duncan \& Magnuson, 2011; Farkas \& Beron, 2004; Hoff, 2003, 2006).

Interventions addressing these children's language abilities have been the subject of much research focusing on which types of intervention are most effective. For example, children learn words better when they are presented in context, rather than in isolation, which deepens children's understanding of the meanings of the new words (Christie \& Roskos, 2006; Harris, Golinkoff, \& Hirsh-Pasek, 2011; Miller \& Gildea, 1987). Stories can provide such a context: Children who hear new words in the course of a story are likely to learn those words (de Jong \& Bus, 2002; Elley, 1989; Elley \& Mangubhai, 1983; Ganea, Pickard, \& DeLoache, 2008). Providing the new words' definitions during the reading of the story is especially helpful to learning (Biemiller, 2006; Biemiller \& Boote, 2006; Brabham \& Lynch Brown, 2002; Elley, 1989; Penno, Wilkinson, \& Moore, 2002). Play situations may also offer a supportive context for word learning (Glenberg, Gutierrez, Levin, Japuntich, \& Kaschak, 2004; Han, Moore, Vukelich, \& Buell, 2010; Roskos \& Christie, 2013). A particularly effective type of play is guided play, in which attentive adults structure the play environment and scaffold children's learning (see Lillard et al., 2013; Weisberg, Zosh, Hirsh-Pasek, \& Golinkoff, 2013, for reviews). These studies suggest that children can learn new words through book-reading and play activities, and they may learn particularly well if these activities are interactive and personally meaningful.

Although many programs focus on the form of intervention, few have examined the content of intervention activities, specifically whether this content is realistic or fantastical. This is an important issue to address because the content of a story can affect children's engagement and hence their learning. We directly address this question by systematically varying the context in which the new words are presented.

A realistic theme might teach better because it situates new words in a familiar context, allowing children to draw on their own knowledge (Catrambone \& Holyoak, 1989; Ganea et al., 2008; Ganea, Allen, Butler, Carey, \& DeLoache, 2009; Spencer \& Weisberg, 1986). However, some evidence suggests that fantastical or imaginative contexts can benefit preschoolers' thinking abilities. For example, these contexts have been shown to boost preschoolers' abilities to reason counterfactually (Buchsbaum, Bridgers, Weisberg \& Gopnik, 2012; Dias \& Harris, 1988, 1990; Scott, Baron-Cohen, \& Leslie, 1999), to understand improbable events (Weisberg \& Sobel, 2012), and to conceptualize pretend actions (Lillard \& Sobel, 1999; Sobel, 2006). These findings imply that context can make a difference to children's reasoning skills and that the inclusion of fantastical elements in a word-learning context could be an effective teaching strategy for vocabulary.

We investigate this issue as part of a large-scale study on children's word learning, conducted in low-income preschool classrooms (see Newman, Dickinson, Golinkoff, \& Hirsh-Pasek, submitted for publication; Hadley, Dickinson, Hirsh-Pasek, \& Golinkoff, submitted for publication, for descriptions of other aspects of the study; results of the full intervention will be published separately). In this study, groups of three children were presented with 20 new vocabulary words in the context of a bookreading activity. The meanings of the new words were further reinforced in a 10-minute play activity following the bookreading. The full study involved three different play conditions to determine how teachers 
can best use play to reinforce the meanings of the new words. One third of the children in the full sample engaged in free play $(n=81)$, and the rest of the children $(n=154)$ engaged in one of two forms of adult-supported play. Our main analyses indicate that children in the free play condition learned the new words significantly less well than children in the other two conditions (see below for details of the testing procedures), while the two adult-supported play conditions did not differ. Because we focus here specifically on whether there are differences in learning based on theme (Realistic or Fantastical), data from only those children who engaged in the two adult-supported play conditions are included.

Roughly half of the children in the present study were presented books focusing on Realistic themes (farming and cooking), and the remainder were presented books focusing on Fantastical themes (dragons and castles). The main goal was to determine whether the degree of children's learning would vary by context. As suggested above, we predict that children in the Fantastical group will learn the new words more effectively than children in the Realistic group.

\section{Method}

\subsection{Participants}

We examined the performance of 154 preschool-aged children enrolled in state- or federallyfunded pre-kindergarten programs, such as Head Start, targeted at low-income populations. Included were 93 females, mean age 59.6 months, $\mathrm{SD}=4.4$ months, range $44-66$ months. Initially, 168 participants were recruited, but 14 children were excluded from the final analyses for failing to complete post-testing due to repeated absences during the post-testing period or refusal to engage in the tasks.

Children were recruited from two project sites, one near Nashville, $\mathrm{TN}(n=99)$ and one in the Lehigh Valley, PA $(n=55)$. Recruitment procedures were the same for both sites. After obtaining permission from the preschool administration, we distributed consent forms to 28 classrooms ( 18 in Tennessee and 10 in Pennsylvania). Teachers were requested to obtain parental permission for children in their classroom who spoke English with their peers, could understand instructions in English, and who did not have an Individualized Education Program (IEP) that would indicate developmental delay or interfere with their participation in our intervention.

Six children from each classroom participated in groups of three. The majority of these groups (70\%) were mixed-gender. Theme assignments were randomized at the classroom level. Children in half of the classrooms (14) received the Realistic theme ( $n=75,42$ female, mean age $=59$ months) and children in the other half of the classrooms (14) received the Fantastical theme ( $n=79,51$ female, mean age $=60$ months).

Although all children were able to engage in the intervention in English, 21 were English language learners (ELL) and spoke other languages at home. The proportion of such children included in the intervention did not differ across conditions (10 in the Realistic theme condition and 11 in the Fantastical theme condition).

\subsection{Intervention Materials}

\subsubsection{Storybooks}

We selected four commercially available children's books to use as the basis of the bookreading portion of the intervention. Each book focused on an interpersonal problem that was solved at the end of the narrative. For the Realistic theme, these books were Farmer Duck (Waddell, 1996), in which farm animals stage a coup after a lazy farmer forces a duck to do all of the work around his farm, and Pumpkin Soup (Cooper, 2005), in which three animal friends argue about who will do which task in making pumpkin soup. For the Fantastical theme, the books were Knight and Dragon (dePaola, 1998), in which a somewhat inept knight and dragon attempt to fight each other, and Dragon for Breakfast (McMullen \& McMullen, 1990), in which a dragon hatches from a king's breakfast egg and annoys the castle staff. Crucially, although all books contained some unrealistic elements that are common to children's books (e.g., talking animals), only the books in the Fantastical theme focused on entities that do not exist in reality (e.g., dragons). 
Table 1

Words used in the intervention, by Theme and Word Type.

\begin{tabular}{|c|c|c|}
\hline & Realistic Theme & Fantastical Theme \\
\hline \multirow[t]{20}{*}{ Target words } & Rung & Talons \\
\hline & Weeds & Scales \\
\hline & Lane & Nostrils \\
\hline & Cabin & Valley \\
\hline & Chimney & Spectacles \\
\hline & Dawn & Handkerchief \\
\hline & Quarrel & Servants \\
\hline & Sorrow & Throne \\
\hline & Fetched & Enemies \\
\hline & Returned & Foolishness \\
\hline & Fled & Galloped \\
\hline & Trotted & Rummaged \\
\hline & Paced & Charged \\
\hline & Slurped & Chuckled \\
\hline & Weighty & Emerged \\
\hline & Wearily & Stamped \\
\hline & Peaceful & Fierce \\
\hline & Scrumptious & Intelligent \\
\hline & Above & Below \\
\hline & Over & Onto \\
\hline \multirow[t]{9}{*}{ Exposure words } & Fields & Shield \\
\hline & Wheelbarrow & Pond \\
\hline & Stool & Quilt \\
\hline & Tip & Platter \\
\hline & Plan & Reflection \\
\hline & Meeting & Exhaled \\
\hline & Wept & Accidentally \\
\hline & Sobbed & Speechless \\
\hline & & Petite \\
\hline \multirow{8}{*}{ Control words } & Stream & Heel \\
\hline & Hedge & Pliers \\
\hline & Curtain & Vase \\
\hline & Journey & Celebration \\
\hline & Plummeted & Grumbled \\
\hline & Lugged & Scowled \\
\hline & Recent & Flexible \\
\hline & Adjacent & Supported \\
\hline
\end{tabular}

\subsubsection{Vocabulary words}

We included three types of words: Target, Exposure, and Control (see Table 1 for full set of words). Target words were taught through explicit definitions, model usage in sentences, and illustrative gestures. These words were used both in the bookreading sessions and in the play sessions. Exposure words were included in the books and play sessions but were never explicitly taught. These words were included to assess children's abilities to learn words incidentally. Finally, Control words were never present in either the bookreading or play sessions but were included in the pre- and post-tests to investigate general vocabulary growth over the course of the two-week intervention.

Each book contained 10 words that were the target of the intervention (Target words). Hence, each child was taught 20 new words over the course of the intervention ( 2 books with 10 Target words each). Each book also contained 4 or 5 Exposure words for a total of 8 (Realistic) or 9 (Fantastical) Exposure words per theme. Eight Control words per theme were included in the pre- and post-vocabulary tests.

These words were chosen from lists in Biemiller (2009) to control for how well they are typically known by four-year-olds. They were chosen to reflect a variety of form classes (nouns, verbs, adjectives, and prepositions), be above preschoolers' knowledge level, and (for the Target and Exposure words) fit naturally into the text of our chosen books. Apart from these constraints, words were chosen randomly from the lists and were randomly assigned to one of the three word types. Although all of the words for all three types were matched for difficulty according to standards described in Biemiller (2009), 
we found some slight differences between them at pre-test. Taught words were less well known than Exposure words on both tasks: Comprehension task: $t(306)=8.07, p<0.01$, Cohen's $d=0.92,95 \%$ CI $[0.11,0.18]$; Production task: $t(306)=6.22, p<0.01$, Cohen's $d=0.71,95 \% \mathrm{CI}[0.17,0.33]$; see details below about testing procedures) and were less well known than Control words on the Comprehension task: $t(306)=4.81, p<0.01$, Cohen's $d=0.55,95 \% \mathrm{CI}[0.05,0.12]$. Exposure words were more well known than Control words on both tasks: Comprehension: $t(306)=3.06, p<0.01$, Cohen's $d=0.35,95 \% \mathrm{CI}[0.02$, $0.10]$; Production: $t(306)=5.03, p<0.01$, Cohen's $d=0.57,95 \% \mathrm{CI}[0.12,0.29]$. While these analyses indicate that the words from these three categories were not perfectly matched in terms of prior knowledge, it was the Target words that were the most challenging for children, providing a more stringent test of our intervention.

\subsubsection{Book texts}

We chose commercially available books for this study so that these materials could be most easily implemented in other classrooms. Because of this, the exact structure of the stories and the words that we included were somewhat different across themes. To address this issue, we slightly modified the texts of the books so that they included exactly one usage of each of the Target and Exposure words. We additionally ensured that all four books were matched for overall length, total number of words, number of words per page, and total number of pages. In addition, we integrated all of the words into the books in parallel ways, so that they were all represented by pictures in the books and were all equally important to the action.

\subsubsection{Bookreading scripts}

We created four teaching scripts to accompany each book. These scripts highlighted each word as it appeared in the course of the story and reviewed each word after the reading. For example, one of the Target words in the Fantastical theme was "emerge." The text in the book read, "A little dragon with smoke coming from his nose emerged from the egg." Immediately after this sentence appeared in the book, the accompanying script defined the word for the children: "The little dragon came out of the egg; he emerged from it. See how Grog is emerging from the egg?" After the end of the book, the script reviewed all of the words, using the pictures in the book and hand gestures (when possible) as a guide: "And who is this? [point to picture in book] Yes, Grog, the little dragon who just emerged from the egg. Can you use your hands and help me act out what he did? [cover one hand with other] He emerged [poke one finger through as you say it] from the egg." Although not all words supported the use of gestures, Target words were defined and highlighted in this general fashion during each bookreading session. The exact text of the script varied slightly across the four days when that book was read. Thus, while the book texts themselves contained exactly one mention of each Target and Exposure word, children heard the Target words more over the course of the intervention due to the attention paid to them in these accompanying scripts.

\subsubsection{Play sets}

Each book was associated with a set of replica toys that was used in the play session that followed each reading. Some of these toys were used in the play session for both books in the theme, most notably a large set piece: a castle for the Fantastical theme and a farmhouse for the Realistic theme. A subset of the toys was associated with a particular book (e.g., a pumpkin for Pumpkin Soup) and was only used during the four days when that book was read, not for the other book in that theme (e.g., the pumpkin did not appear in the toy set for Farmer Duck).

\subsubsection{Play scripts}

Like the bookreading portion of the intervention, the play sessions also had scripts for defining and using the Target words. For example, some scripts encouraged the children to act out a section of the book with their props, while other scripts asked children open-ended questions about some aspect of their play. Target words were used in the course of giving these instructions or asking these questions. In both themes, each Target word was scripted to be used three times in a play session and defined once. 


\subsection{Bookreading and Play Intervention Procedure}

Bookreading and play sessions were conducted by a trained individual referred to as an Intervention Specialist (IS), who was different from the children's classroom teachers and from the individuals who administered the pre- and post-tests. The ISs were individuals with some experience with children and/or a background in early childhood education (e.g., former preschool teachers, children's librarians, students in the process of earning their teaching certificates). They were recruited from the areas in which the participating schools were located. During a two-day training session before the start of the intervention, all ISs learned about the intervention method and practiced delivering the bookreading and play scripts. They were observed during these practices by a member of the research team and were corrected as necessary to ensure that they maintained fidelity to the scripts.

Each IS carried out the intervention with groups of three children. Within each classroom, children were randomly assigned to groups, without regard for friendship or gender, though we attempted to construct groups that were mixed-gender whenever possible. These groups remained the same over the course of the intervention, and the same IS worked with that group throughout the intervention.

The first week of the intervention involved reading one book to the group of three children for four consecutive days. The following week, the IS read a second book on the same theme to the group. On each of the 8 days of the intervention, one intervention group of three children was taken out of the classroom to a quiet area to listen to the book and play with the toys. Each day's bookreading took about 10 minutes and was followed by a 10-minute play session with replica toys that matched the characters and other props mentioned in the story. ISs supported the children's play by using the provided scripts, as described above.

Each IS was assessed for fidelity of delivery of the intervention by having a member of the research team observe three of her sessions and note any deviations from the bookreading or play script (e.g., missed definitions). All ISs were deemed to be delivering the intervention within appropriate parameters: less than $10 \%$ deviation per session. Informal observation of the intervention sessions, both during these assessments and via a review of a subset of the recordings, indicated that children were highly engaged in both the bookreading and the play sessions for both themes.

Across classrooms, we counterbalanced the theme of the books and play materials, as well which of the two books from the theme was read first.

\subsection{Testing Materials and Procedure}

Children's knowledge of the Target, Exposure, and Control words was assessed before and after the two-week intervention using both a Comprehension (receptive) and Production (expressive) vocabulary measure. For each child, testing was performed by a different person than the IS who had delivered that child's intervention, either a different IS or a member of the research team.

\subsubsection{Vocabulary comprehension task}

This task was modeled on the Peabody Picture Vocabulary Test (Dunn \& Dunn, 2007) and similar assessments. The pictures used for this task were downloaded from publicly available sources on the Internet. They were not taken from the books in order to better assess children's generalization of the words. Within each item, the pictures were matched for perceptual features (e.g., all three pictures were photographs, never two photographs and a line drawing).

All of the Target words for each theme (20) and all of the Control words for each theme (8) were included on the Comprehension task. This task included 6 of the 8 Exposure words in the Realistic theme and 8 of the 9 Exposure words in the Fantastical theme. Not all of the Exposure words were presented because some words were too difficult to depict (e.g., "accidentally"); the words that were not included on this task were included on the Production task. In addition, 4 training items and 4 filler items were included, the latter spread randomly throughout the task. These items were ones that children would almost certainly know (e.g., "sleeping"), hence were used to introduce the task or to give children a chance to experience success and receive positive feedback during the task.

To administer this task, an experimenter asked children to choose a target from among three pictures, which were presented on a printed page in a binder (e.g., "Where's the X?", "Can you show 
me X-ing?"). One of two foils was a conceptual match to the target word's meaning, and the other was a thematic match. For example, for the word "cabin," the conceptual foil was a tent and the thematic foil was a pile of logs.

At the beginning of the task, children were told that their job was to point to the picture that matched the word that the tester said. These instructions were followed by 4 training trials, all of which used words that children of this age should know (e.g., "fish"). Children received positive feedback on these trials and corrective feedback if necessary. Following were 34 (for children in the Realistic theme) or 36 (for children in the Fantastical theme) test trials. Children never received specific feedback on their performance on these trials. These trials were interspersed with 4 filler trials, which again involved easy words. On these filler trials, the experimenter provided children with praise for correct answers.

\subsubsection{Vocabulary production task}

This task, the New Word Definition Test-Modified (NWDT-M; see Hadley et al., submitted for publication) builds on another curriculum-specific depth measure, the New Word Definition Test (NWDT; Blewitt, Rump, Shealy, \& Cook, 2009). The goal of this task was to encourage children to report as much information as they could about a given word. It did not require any materials beyond the test prompt. Because of the length of time it took to administer the items on this task, only a subset of the words from each theme was included (18 in the Realistic theme and 21 in the Fantastical theme). These words were chosen randomly while respecting the overall proportion of words in each category (i.e., Target, Exposure, and Control) for each theme condition.

During this task, children were asked to tell the experimenter everything they knew about a word: "What are weeds?" or "Do you know what the word 'weeds' means?" if the child said he or she didn't know, the experimenter moved to the next word. If the child provided any response, the experimenter prompted him or her further, e.g., "Can you tell me anything more about weeds?" A similar prompt was offered twice or until the participant indicated that he or she had nothing more to say about that word. There were 2 training items to get children used to the task and 2 filler items interspersed throughout. As in the Comprehension task, these training and filler items presented words that children this age should know (e.g., "baby"), and the experimenter gave children positive feedback for their correct responses to these items.

We counterbalanced which test was given first at each testing point for each child. Within each test, the words were presented according to one of two random orders. We counterbalanced which of these two random orders each child received across pre- and post-test (i.e., a child who received Order 1 of a given test at pre-test would receive Order 2 of that test at post-test). During the test trials of both tasks, participants were provided general positive feedback ("you're doing great!") but no specific feedback on their performance.

The same items were used in both tests at both time points (albeit in a different order), raising a question of whether children might remember some of the items, especially for the Comprehension task where there were pictures. However, children never received feedback about the correctness of their responses on either task. So while they might have recognized some of the words or pictures, they would not be able to deduce from this knowledge how to respond correctly. Furthermore, there was a minimum of 3 weeks, and usually closer to 4 weeks, between pre- and post-test, making it a challenge for children to remember individual items. Finally, even if children found some items familiar at post-test due to their appearance on the pre-test, this familiarity should be equal across all three word types and hence should not interfere with any effect of word type.

\subsection{Coding}

\subsubsection{Comprehension task}

We counted the number of correct responses (points to the picture that matched the prompt) for each child. Slightly different numbers of words were included from each word type (Target, Exposure, Control) and each theme (Realistic, Fantastical). We thus conducted analyses on the proportion of words in each category to which children responded correctly. 


\subsubsection{Production task}

We coded children's open-ended responses to the prompt for total number of information units, defined as any aspect of a child's response that indicated they knew what the word meant, including synonyms, functions, or gestures. We conducted our main analyses on proportions of information units provided. Proportions were calculated by summing all of the information units provided about the words of each type and dividing this raw score by the total number of words of that type used.

Some categories of information units were the same as those in the NWDT (Blewitt et al., 2009), on which this task was based. However, the NWDT was designed for use only with concrete nouns and does not award any points for meaningful use of a target word in a typical context or for nonverbal, gestural representations of knowledge. We included additional categories to capture a wider range of children's knowledge across a variety of word forms. Children received credit for providing a superordinate or subordinate term related to the object (nouns only), a function of the object (nouns only), a perceptual feature (nouns only), a part of the object (nouns only), a synonym, an antonym, a gesture indicating understanding of the word's meaning, or a statement that used the word in an appropriate context or provided other meaning-related information (e.g., saying "Santa Claus" in response to the word "chimney"). For example, for the word "handkerchief," a child could say, "use for your tears, made out of cloth" and mime wiping her nose. This response would receive 3 points for its inclusion of a function, a perceptual feature, and a gesture.

Each child's responses to the Production task were coded by two independent coders. Coders were required to first meet at least $90 \%$ reliability with a Gold Standard coder. After every fourth set of responses (that is, for $20 \%$ of total responses), coders were required to code an additional set of responses (randomly selected from the set and consistent across coders) and to send these codes to the Gold Standard coder to check for reliability. If the codes for this set of responses were at least $90 \%$ in agreement with the Gold Standard's codes, the coder continued. Otherwise, she was given feedback on where her codes differed and was required to complete an additional set of responses to recalibrate. The average percent agreement among all coders was $93.2 \%(\mathrm{kappa}=0.82$ ). All codes were thus included in the final data set, even if they came from the four forms done before a coder failed a reliability check.

\section{Results}

Preliminary analyses showed no main effects or interactions with gender, so this variable is not considered further. There were also no main effects or interactions with children's ELL status; these children responded to the intervention in the same way as their monolingual peers. The main analyses were thus performed on the entire group of children. Additionally, there were no effects of test order and no interaction effects between test order and Theme: Regardless of whether they received the Comprehension or Production task first, children's performance did not vary at either time point on the Comprehension task pre-test: $F(1,150)=0.12, n s$; post-test: $F(1,150)=0.60, n s)$ - or on the Production task - pre-test: $F(1,150)=0.02$, ns; post-test: $F(1,150)=0.09, n s$.

\subsection{Comprehension Test}

We conducted a 2 (Theme: Realistic vs. Fantastical, between-subjects) $\times 2$ (Time: pre-test vs. post-test, within-subjects) $\times 3$ (Word Type: Target, Exposure, Control, within-subjects) mixed-design analysis of variance (ANOVA) on Comprehension test scores (Table 2). This test showed main effects of all three variables: Time, $F(1,152)=153.03, p<0.01, \eta^{2}=0.11$; Theme, $F(1,152)=11.51, p<0.01, \eta^{2}=0.03$; and Word Type, $F(2,304)=13.86, p<0.01, \eta^{2}=0.02$. There were also interactions between Word Type and Theme, $F(2,304)=17.64, p<0.05, \eta^{2}=0.03$, and between Word Type and Time, $F(2,304)=38.84, p<0.01, \eta^{2}=0.06$.

The main effect of Time occurs because post-test scores $(M=0.59, \mathrm{SD}=0.14)$ were significantly higher than pre-test scores $(M=0.43, \mathrm{SD}=0.10)$. The main effect of Theme occurs because scores were significantly higher overall for the Realistic theme $(M=0.53, \mathrm{SD}=0.20)$ than for the Fantastical theme $(M=0.48, \mathrm{SD}=0.17)$. The main effect of Word Type occurs because overall scores for Exposure words $(M=0.54, \mathrm{SD}=0.20)$ were higher than scores for Target words $(M=0.49, \mathrm{SD}=0.18)$ and Control words $(M=0.48, \mathrm{SD}=0.18)$.

Because of the interactions involving Word Type, we conducted separate Time $\times$ Theme analyses for each of the three word types. All three word types showed a main effect of Time (post-test scores significantly higher than pre-test scores). No main effect of Theme emerged for the Target or Control words, but the Exposure words did show a main effect of Theme, $\left.F(1,152)=32.62, p<0.01, \eta^{2}=0.13\right)$. Children responded more accurately overall to the exposure words in the Realistic theme $(M=0.61, \mathrm{SD}=0.21)$ than to the exposure words in the Fantastical theme $(M=0.47, \mathrm{SD}=0.16)$. This difference accounts for the main effect of Theme and the interaction of Theme and Word Type noted above: Although words in the Realistic theme appeared to be more well-known overall, this is due to the fact that only the Exposure words show a theme difference. Importantly, there 
Table 2

Mean proportion of words on the Comprehension task known at pre- and post-test, by Theme and Word Type.

\begin{tabular}{llll}
\hline & & \multicolumn{2}{l}{ Theme } \\
\cline { 3 - 4 } & & Realistic & Fantastical \\
\hline Target & Pre-test & $0.37(0.13)$ & $0.37(0.12)$ \\
words & Post-test & $0.61(0.16)$ & $0.60(0.16)$ \\
Exposure & Pre-test & $0.57(0.20)$ & $0.46(0.14)$ \\
words & Post-test & $0.66(0.22)$ & $0.49(0.17)$ \\
Control & Pre-test & $0.47(0.17)$ & $0.44(0.17)$ \\
words & Post-test & $0.53(0.20)$ & $0.51(0.17)$ \\
\hline
\end{tabular}

Note: Standard deviations are in parentheses.

Table 3

Mean proportion of information units provided per word for words on the Production task at pre- and post-test, by Theme and Word Type.

\begin{tabular}{lllr}
\hline & & \multicolumn{2}{l}{ Theme } \\
\cline { 3 - 3 } & & Realistic & Fantastical \\
\hline Target & Pre-test & $0.23(0.28)$ & $0.08(0.12)$ \\
words & Post-test & $0.60(0.47)$ & $0.66(0.53)$ \\
Exposure & Pre-test & $0.34(0.37)$ & $0.46(0.51)$ \\
words & Post-test & $0.48(0.41)$ & $0.61(0.48)$ \\
Control & Pre-test & $0.13(0.17)$ & $0.26(0.27)$ \\
words & Post-test & $0.17(0.20)$ & $0.38(0.31)$ \\
\hline
\end{tabular}

Note: Standard deviations are in parentheses.

were no interactions between Theme and Time for any of the three word types; differences between the two Themes were stable across the intervention.

\subsection{Production Test}

We first conducted a 2 (Theme: Realistic vs. Fantastical, between-subjects) $\times 2$ (Time: pre-test vs. post-test, withinsubjects) $\times 3$ (Word Type: Target, Exposure, Control, within-subjects) mixed-design ANOVA on Production scores (Table 3 ). This test revealed main effects of Time, $F(1,152)=182.69, p<0.01, \eta^{2}=0.09$, and Word Type, $F(2,304)=48.03, p<0.01, \eta^{2}=0.07$, and a marginal effect of Theme, $F(1,152)=3.63, p=0.06, \eta^{2}=0.01$.

The main effect of Time occurs because post-test scores $(M=0.58, \mathrm{SD}=0.43)$ were higher than pre-test scores $(M=0.23$, $\mathrm{SD}=0.23)$, as expected. The main effect of Word Type occurs because overall scores were highest for Exposure words $(M=0.47$ $\mathrm{SD}=0.45)$, then for Target words $(M=0.39, \mathrm{SD}=0.46)$, then for Control words $(\mathrm{M}=0.24, \mathrm{SD}=0.26)$. The marginal effect of Theme reflects higher scores in the Fantastical condition $(M=0.41, \mathrm{SD}=0.44)$ than in the Realistic condition $(M=0.33, \mathrm{SD}=0.37)$.

There were also interactions between Word Type and Time, $F(2,304)=53.95, p<0.01, \eta^{2}=0.05$, Word Type and Theme, $F(2,304)=10.44, p<0.01, \eta^{2}=0.02$, and Time and Theme, $F(1,152)=8.11, p<0.01, \eta^{2}=0.004$, and a marginally significant three-way interaction, $F(2,304)=2.90, p=0.06, \eta^{2}=0.003$. Due to the interactions with Word Type, we conducted separate Time $\times$ Theme ANOVA analyses for each word type.

For Target words, there was an effect of Time, $F(1,152)=193.64, p<0.01, \eta^{2}=0.28$, with post-test scores $(M=0.63, S D=0.50)$ higher than pre-test scores $(M=0.15, S D=0.23)$. There was no effect of Theme, but this test did reveal a significant interaction between Theme and Time, $F(1,152)=8.94, p<0.01, \eta^{2}=0.02$. Pre-test scores were lower for the Fantastical theme $(M=0.08$, $\mathrm{SD}=0.12)$ than the Realistic theme, $(M=0.23, \mathrm{SD}=0.28 ; t(152)=4.16, p<0.01$, Cohen's $d=0.68,95 \% \mathrm{CI}[0.07,0.21])$, but posttest scores did not differ (Fantastical theme $M=0.66, S D=0.53$; Realistic theme $M=0.60, S D=0.47 ; t(152)=0.72, n s$ ). That is, children's productive knowledge made significantly greater gains in the Fantastical than in the Realistic theme.

A potential reason is that children may have heard or used the Target words more in the Fantastical theme. Although both bookreading and play interactions were scripted, the adults or children may have incorporated additional usages of the words into their talk during the learning phase, leading to unequal exposure across themes that could explain the difference. To test this explanation, we examined a randomly selected subset of the recordings from the play sessions (16). These analyses indicate that the adults used the Target words significantly more often in the Realistic theme $(M=33.5$ words per session, $S D=11.19)$ than in the Fantastical theme $(M=21.25$ words per session, $\mathrm{SD}=5.87 ; t(14)=2.74, p=0.02$, Cohen's $d=1.47)$. Although children rarely used the Target words during the play sessions, like the adults they tended to say the words more in the Realistic theme 
$(M=2.5$ words per session, $\mathrm{SD}=2.2)$ than in the Fantastical theme $(M=0.75$ words per session, $\mathrm{SD}=1.04 ; t(14)=2.03, p=0.06)$. Superior learning in the Fantastical theme is thus unlikely to be due to greater exposure to or usage of the words in this theme. It is still possible that something about the Fantastical theme was more engaging, even if this engagement was not reflected in additional word usage, a possibility we return to in the Discussion (see also Ilgaz, Weisberg, Hirsh-Pasek, Golinkoff, \& Nicolopoulou, 2013).

Because the Production test considers proportion of information units provided per word, higher post-test scores might be the result of children producing more information units about the same words that they knew at pre-test (i.e., the intervention led them to deepen their knowledge of those words that they already knew), or they might be the result of children producing information units for more of the words (i.e., the intervention led them to learn new words). To investigate these alternatives, we conducted a series of paired $t$-tests on children's pre- and post-test scores for the individual Target words that were included on the Production test, using Bonferroni corrections for multiple comparisons. These tests revealed that children produced more information units per word at post-test for 7 of the 8 Target words in the Realistic theme that were included on the Production test and for 12 of the 13 Target words in the Fantastical theme that were included on the Production test. This indicates that, even if children already knew some of the Target words at pre-test, they gained more information about these words as a result of our intervention.

We additionally counted the number of Target words for which children produced any information units at pre-test and post-test and compared these counts using paired $t$-tests. Children produced information units about significantly more of the Target words at post-test than at pre-test, for both the Realistic theme (pre-test $M=1.56$ words, $S D=1.55$; post-test $M=3.67$ words, $\mathrm{SD}=2.21 ; t(77)=11.06, p<0.01$, Cohen's $d=2.52,95 \% \mathrm{CI}[1.72,2.48]$ ) and the Fantastical theme (pre-test $M=1.01$ words, $\mathrm{SD}=1.28$; post-test $M=5.60$ words, $\mathrm{SD}=3.70 ; t(79)=13.01, p<0.01$, Cohen's $d=2.93,95 \% \mathrm{CI}$ [3.89, 5.29]). Importantly, these results indicate that children learned about target words that they could not provide information about before.

For Exposure words, there was a main effect of Time, $F(1,152)=20.88, p<0.01, \eta^{2}=.03$, but no effect of Theme and no Time $\times$ Theme interaction on Production test performance. For Control words, there was a main effect of Time, $F(1,152)=15.10$, $p<0.01, \eta^{2}=0.03$, and a main effect of Theme, $F(1,152)=25.39, p<0.01, \eta^{2}=0.11$. Scores for the Fantastical theme $(M=0.32$, $\mathrm{SD}=0.29)$ were significantly higher than for the Realistic theme $(M=0.15, \mathrm{SD}=0.18)$. However, there was no interaction with Time; these differences remained stable between pre- and post-test, indicating that children did not learn the Control words at different rates in the different themes.

\section{Discussion}

Previous work has shown that children can learn new words from storybooks, and the current results confirm these findings. Children in low-income preschool classrooms who heard new vocabulary words presented in books and reinforced through play sessions learned these words over the course of a two-week intervention, and their comprehension learning was equivalent across the Realistic and Fantastical themes. More impressively, children learned the Target words well enough not only to identify them in a test of their comprehension, where guessing was possible, but also to report on aspects of the words' meanings in a test of their productive knowledge. These findings demonstrate that small-group bookreading activities paired with follow-up play activities, regardless of content, can be highly effective for vocabulary learning. This approach differs somewhat from the kind of large-group bookreading and free play activities that are typically found in preschool classrooms. But elements of the current approach (e.g., the use of story-related replica objects) could easily be incorporated into a classroom, and these elements may encourage greater learning.

While children learned the new words in both theme conditions, we found that children in the Fantastical theme condition showed significantly more gains in their productive knowledge of the new words. Because children could not guess the correct answer on the Production test, we consider this test a more sensitive measure of real learning, hence an especially important piece of evidence that fantastical themes can aid children's vocabulary learning.

It is important to note that all of the books we used contained anthropomorphic animals - that is, fantastical entities. If any degree of unreality were sufficient to boost children's learning, we would not have observed differences across our two themes. To the contrary, we found superior word learning when the books presented to children not only included anthropomorphic animals, but also focused on events that cannot occur in reality (e.g., dragons hatching out of breakfast eggs). This strongly suggests that stories focusing on fantastical elements encourage greater learning.

Why should this be the case? Why would books and toys about a fantastical theme, which removes children from their everyday world, be more supportive of word learning? One possibility is that fantastical themes may encourage children to explore new words' meanings more deeply than realistic themes. Engaging with fantastical elements may require greater cognitive processing than engaging with elements that are present in the real world, precisely because these elements defy the laws of 
reality. Such contexts present situations that encourage children to stretch beyond the boundaries of their current knowledge and thereby to access new concepts or thinking patterns (Weisberg, HirshPasek, \& Golinkoff, 2013; Weisberg, Hirsh-Pasek, Golinkoff, \& McCandliss, 2014).

Previous work has shown that encouraging imagination-based thinking enhances various aspects of children's reasoning (Dias \& Harris, 1988; Fisher et al., in preparation; Lillard \& Sobel, 1999; Weisberg \& Sobel, 2012). For example, Hopkins and Lillard (in preparation) presented preschoolers with realistic and fantastical stories, within which was embedded a novel problem solution: A character used a rolled-up newspaper to get pieces of dog food from one side of a fence to a dog's bowl on the other side of the fence. Following the story, children were presented an analogous problem in which they had to transfer marbles into a bowl that was located inside a box. Children were more likely to succeed at the transfer task when they had heard the fantastical story than when they had heard the realistic story (see also Richert \& Schlesinger, submitted for publication). These authors speculate that the fantastical story may have encouraged children to think more flexibly, hence to be more likely to succeed on the problem-solving task. A similar process may have occurred in the case of our stories. In addition, children's interactions with fictional stories generally tend to rely on their understanding of reality and rarely stray far from facts that they know to be true in reality (Sobel \& Weisberg, 2014; Weisberg, Sobel, Goodstein, \& Bloom, 2013). Having an adult provide them with permission to venture outside of an everyday context may thus be especially beneficial to their imaginative thinking and to their focused engagement with the word-learning task.

These sets of results may explain why the Fantastical theme enhanced children's performance on our expressive vocabulary test. Fantasy elements engage children's imaginations, encouraging them to process the new words more fully and hence to understand them more deeply. It was this deeper understanding that was tapped by the Production test, which required children to recall and report word meanings. Other research has shown that educational games with fantasy story content that is meaningful to children can promote greater immersion in the game and hence better learning (Gunter, Kenny, \& Vick, 2008).

A more deflationary possibility is that books and play materials exploring a fantastical theme may simply be more interesting to children than those exploring a realistic theme. A fantastical theme, by definition, includes elements that are not present in children's everyday lives and may thus encourage greater attention to the stories and hence to the words presented within the stories. A related possibility is that the Fantastical theme elicited more participation from children, because they were eager to engage with props and ideas that were outside of their usual experience and that broadened the range of possibilities they could explore in play. This argument relies on findings that children learn better in contexts where they are active, engaged participants (Chi, 2009; Honomichl \& Chen, 2012; Weisberg, Hirsh-Pasek, et al., 2013). The inclusion of fantastical elements could provide a simple way to create such learning contexts in a classroom setting. According to this argument, however, fantasy is not a necessary component of such learning contexts.

One way to distinguish between these possibilities would be to pit contexts that are strictly impossible and that contain violations of natural laws against contexts that are merely unusual or unfamiliar to children. If the deflationary account is correct, both of these contexts will lead to superior learning when compared to realistic contexts, but there should be no difference between them. However, if the first account is correct, there should be an additional benefit to the fantastical contexts over and above any benefit due to the unusual contexts. On this argument, it is precisely the act of engaging with entities and events that are impossible in reality that leads to improved learning. Future studies should examine these types of scenarios in more detail, as well as match words and books more tightly across themes, to determine how best to explain the present results. Future research should also focus on which elements of the stories children chose to explore in their play, under what circumstances children used the new words in their play, whether children continue to use the new words outside of the intervention setting, and children's overall levels of attention and engagement. These analyses will provide additional clues as to which aspects of the fantastical stories were most facilitative of learning.

Both of the possible explanations that we have offered here are somewhat at odds with work suggesting that linking new vocabulary words to familiar contexts helps children to learn (Christie \& Roskos, 2006; Ganea et al., 2008, 2009; see also Richert, Shawber, Hoffman, \& Taylor, 2009; Walker, 
Gopnik, \& Ganea, in press). But the logic behind both suggestions can be explained using the mise en place construct (Weisberg et al., 2014), which highlights the crucial role played by children's attitudes toward a learning environment. Children hearing books about realistic themes may see these bookreading sessions as more "business as usual," and may not bring their full attention and engagement to the task. But children hearing books about fantastical themes may use the impossible or unusual nature of this situation as a clue to engage more fully, because something in this situation is special and different.

Finally, when thinking about constructing potential classroom interventions, the reasons behind the effect become somewhat less important than the effect itself. Our results strongly suggest that including fantastical themes in preschool classrooms can be highly beneficial to children's learning of new vocabulary. Such themes may benefit children's learning of other facts and skills as well, and as such merit inclusion in the curriculum.

\section{Acknowledgements}

The authors would like to thank the children, teachers, parents, and administrators at the two project sites for their generous cooperation with our research, as well as our team of Intervention Specialists. We would also like to thank our collaborators for their assistance with the design, implementation, and analysis of the full project on which this paper is based: Molly Fuller Collins, Elizabeth B. Hadley, Kimberly T. Nesbitt, and Bretta L. Rivera. The Comprehension measure was created by Hilary Miller and Sujeet Ranganathan at the University of Delaware. Thanks also to Andrea Nuschke for her assistance in coordinating and implementing the intervention. This project was funded by the Institute of Education Sciences (grant \#R305A110128).

\section{References}

Biemiller, A. (2006). Vocabulary development and instruction: A prerequisite for school learning. In D. K. Dickinson, \& S. B. Neuman (Eds.), Handbook of early literacy research (Vol. II) (pp. 41-51). New York, NY: Guilford.

Biemiller, A. (2009). Words worth teaching. Columbus, OH: SRA/McGraw-Hill.

Biemiller, A., \& Boote, C. (2006). An effective method for building meaning vocabulary in primary grades. Journal of Educational Psychology, 98(1), 44-62.

Blewitt, P., Rump, K. M., Shealy, S. E., \& Cook, S. A. (2009). Shared book reading: When and how questions affect young children's word learning. Journal of Educational Psychology, 101(2), 294.

Brabham, E. G., \& Lynch Brown, C. (2002). Effects of teachers' reading-aloud styles on vocabulary acquisition and comprehension of students in the early elementary grades. Journal of Educational Psychology, 94, 465-473.

Buchsbaum, D., Bridgers, S., Weisberg, D. S., \& Gopnik, A. (2012). The power of possibility: Causal learning, counterfactual reasoning, and pretend play. Philosophical Transactions of the Royal Society B, 367, 2202-2212.

Catrambone, R., \& Holyoak, K. J. (1989). Overcoming contextual limitations on problem-solving transfer. Journal of Experimental Psychology: Learning, Memory, and Cognition, 15, 1147-1156.

Chi, M. T. H. (2009). Active-constructive-interactive: A conceptual framework for differentiating learning activities. Topics in Cognitive Science, 1, 73-105.

Christie, J. F., \& Roskos, K. A. (2006). Standards, science and the role of play in early literacy education. In D. G. Singer, R. M. Golinkoff, \& K. Hirsh-Pasek (Eds.), Play=learning: How play motivates and enhances cognitive and social-emotional growth (pp. 57-73). New York: Oxford University Press.

Cooper, H. (2005). Pumpkin soup. New York, NY: Square Fish.

de Jong, M. T., \& Bus, A. G. (2002). Quality of book-reading matters for emergent readers: An experiment with the same book in a regular or electronic format. Journal of Educational Psychology, 94, 145-155.

dePaola, T. (1998). Knight and dragon. New York, NY: Puffin.

Dias, M. G., \& Harris, P. L. (1988). The effect of make-believe play on deductive reasoning. British Journal of Developmental Psychology, 6, 207-221.

Dias, M. G., \& Harris, P. L. (1990). The influence of the imagination on reasoning by young children. British Journal of Developmental Psychology, 8, 305-318.

Dickinson, D. K., \& McCabe, A. (2001). Bringing it all together: The multiple origins, skills, and environmental supports of early literacy. Learning Disabilities Research and Practice, 16(4), 186-202.

Dickinson, D. K., Golinkoff, R. M., \& Hirsh-Pasek, K. (2010). Speaking out for language: Why language is central to reading development. Educational Researcher, 39(4), 305-310.

Duncan, G., \& Magnuson, K. (2011). The nature and impact of early achievement skills, attention and behavior problems. In G. Duncan, \& R. Murnane (Eds.), Social inequality and educational disadvantage. New York: Russell Sage Foundation.

Dunn, L. M., \& Dunn, D. M. (2007). Peabody Picture Vocabulary Test (PPVT IV). San Antonio, TX: Pearson Clinical Assessments. 
Elley, W. B. (1989). Vocabulary acquisition from listening to stories. Reading Research Quarterly, 24, 174-187.

Elley, W. B., \& Mangubhai, F. (1983). The impact of reading on second language learning. Reading Research Quarterly, 19, 53-67.

Farkas, G., \& Beron, K. (2004). The detailed age trajectory of oral vocabulary knowledge: Differences by class and race. Social Science Research, 33, 464-497.

Fisher, K., Glazek, K., Schol, E., Rouse, C., Hirsh-Pasek, K., \& Golinkoff, R. (2015). Pedagogical constraints on children's creative problem-solving skills. (in preparation).

Ganea, P. A., Pickard, M., \& DeLoache, J. S. (2008). Transfer between picture books and the real world by very young children. Journal of Cognition and Development, 9, 46-66.

Ganea, P. A., Allen, M. L., Butler, L., Carey, S., \& DeLoache, J. S. (2009). Toddlers' referential understanding of pictures. Journal of Experimental Child Psychology, 104(3), 283-295.

Gershoff, E. T. (2003). Low income and the development of America's kindergartners. In Living at the edge, Research brief number 4. New York, NY: National Center for Children in Poverty.

Glenberg, A. M., Gutierrez, T., Levin, J. R., Japuntich, S., \& Kaschak, M. P. (2004). Activity and imagined activity can enhance young children's reading comprehension. Journal of Educational Psychology, 96(3), 424-436.

Gunter, G. A., Kenny, R. F., \& Vick, E. H. (2008). Taking educational games seriously: Using the RETAIN model to design endogenous fantasy into standalone educational games. Educational Technology Research and Development, 56, 511-537.

Hadley, E. B., Dickinson, D. K., Hirsh-Pasek, K., \& Golinkoff, R. M. (2015). A detailed approach to assessing preschoolers' depth of word knowledge. (submitted for publication).

Han, M., Moore, N., Vukelich, C., \& Buell, M. (2010). Does play make a difference? Effects of play intervention on at-risk preschoolers' vocabulary learning. American Journal of Play, 3, 82-105.

Harris, J., Golinkoff, R. M., \& Hirsh-Pasek, K. (2011). Lessons from the crib for the classroom: How children really learn vocabulary. In S. B. Neuman, \& D. K. Dickinson (Eds.), Handbook of early literacy research (Vol. 3) (pp. 49-65). New York: Guilford Press.

Hoff, E. (2003). The specificity of environmental influence: Socioeconomic status affects early vocabulary development via maternal speech. Child Development, 74(5), 1368-1378.

Hoff, E. (2006). How social contexts support and shape language development. Developmental Review, 26, 55-88.

Honomichl, R. D., \& Chen, Z. (2012). The role of guidance in children's discovery learning. Wiley Interdisciplinary Reviews: Cognitive Science, 3(6), 615-622.

Hopkins, E. J., \& Lillard, A. S. (2015). The effect of specific fantasy elements on children's learning from storybooks. (in preparation).

Ilgaz, H., Weisberg, D. S., Hirsh-Pasek, K., Golinkoff, R., \& Nicolopoulou, A. (2013). Not all play is created equal: When playful learning sparks vocabulary acquisition in low-income children. Seattle, WA: Paper presented at the biennial meeting of the Society of Research in Child Development.

Lee, V. E., \& Burkham, D. T. (2002). Inequality at the starting gate: Social background differences in achievement as children begin school. New York: Economic Policy Institute.

Lillard, A. S., \& Sobel, D. (1999). Lion kings or puppies: The influence of fantasy on children's understanding of pretense. Developmental Science, 2(1), 75-80.

Lillard, A. S., Lerner, M. D., Hopkins, E. J., Dore, R. A., Smith, E. D., \& Palmquist, C. M. (2013). The impact of pretend play on children's development: A review of the evidence. Psychological Bulletin, 139, 1-34.

McMullen, E., \& McMullen, N. (1990). Dragon for breakfast. Minneapolis, MN: Carolrhoda Books.

Miller, G. A., \& Gildea, P. M. (1987). How children learn words. Scientific American, 257(3), 94-99.

Newman, K., Dickinson, D. K., Golinkoff, R. M., \& Hirsh-Pasek, K. (2015). Using play to promote language comprehension in preschoolers. (submitted for publication).

NICHD Early Child Care Research Network. (2005). Pathways to reading: The role of oral language in the transition to reading. Developmental Psychology, 41(2), 428-442.

Penno, J. F., Wilkinson, I. A. G., \& Moore, D. W. (2002). Vocabulary acquisition from teacher explanation and repeated listening to stories: Do they overcome the Matthew effect? Journal of Educational Psychology, 94(1), 23-33.

Richert, R. A., \& Schlesinger, M. A. (2015). Selective trust and children's learning from fantasy characters. (submitted for publication).

Richert, R. A., Shawber, A. B., Hoffman, R. E., \& Taylor, M. (2009). Learning from fantasy and real characters in preschool and kindergarten. Journal of Cognition and Development, 10, 41-66.

Roskos, K. A., \& Christie, J. F. (2013). Gaining ground in understanding the play-literacy relationship. American Journal of Play, 6(1), 82-97.

Scott, F. J., Baron-Cohen, S., \& Leslie, A. (1999). If pigs could fly: A test of counterfactual reasoning and pretence in children with autism. British Journal of Developmental Psychology, 17, 349-362.

Sénéchal, M. (2006). Testing the home literacy model: Parent involvement in kindergarten is differentially related to grade 4 reading comprehension, fluency, spelling, and reading for pleasure. Journal for the Scientific Study of Reading, 10, 5987.

Sobel, D. M. (2006). How fantasy benefits young children's understanding of pretense. Developmental Science, 9(1), 6375.

Sobel, D. M., \& Weisberg, D. S. (2014). Tell me a story: How children's developing domain knowledge affects their story construction. Journal of Cognition and Development, 15(3), 465-478.

Spencer, R. M., \& Weisberg, R. W. (1986). Context-dependent effects on analogical transfer during problem solving. Memory and Cognition, 14, 442-449.

Storch, S. A., \& Whitehurst, G. J. (2002). Oral language and code-related precursors to reading: Evidence from a longitudinal structural model. Developmental Psychology, 38, 934-947.

Waddell, M. (1996). Farmer duck. Somerville, MA: Candlewick Press.

Walker, C. M., Gopnik, A., \& Ganea, P. (2014). Learning to learn from stories: Children's developing sensitivity to the causal structure of fictional worlds. Child Development (in press).

Weisberg, D. S., \& Sobel, D. M. (2012). Young children discriminate improbable from impossible events in fiction. Cognitive Development, 27, 90-98.

Weisberg, D. S., Hirsh-Pasek, K., \& Golinkoff, R. M. (2013). Guided play: Where curricular goals meet a playful pedagogy. Mind, Brain, and Education, 7(2), 104-112. 
Weisberg, D. S., Sobel, D. M., Goodstein, J., \& Bloom, P. (2013). Young children are reality-prone when thinking about stories. Journal of Cognition and Culture, 13, 383-407.

Weisberg, D. S., Zosh, J. M., Hirsh-Pasek, K., \& Golinkoff, R. M. (2013). Talking it up: Play, language, and the role of adult support. American Journal of Play, 6(1), 39-54.

Weisberg, D. S., Hirsh-Pasek, K., Golinkoff, R., \& McCandliss, B. D. (2014). Mise en place: Setting the stage for thought and action. Trends in Cognitive Sciences, 18(6), 276-278. 